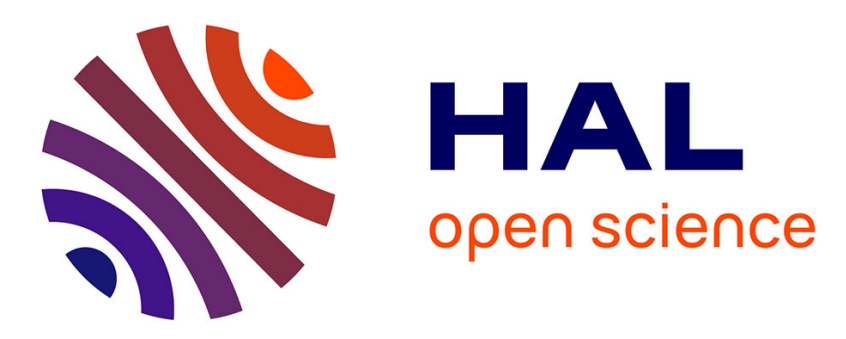

\title{
External auditory exostoses and prehistoric aquatic resource procurement
}

Sébastien Villotte, Christopher J. Knüsel

\section{To cite this version:}

Sébastien Villotte, Christopher J. Knüsel. External auditory exostoses and prehistoric aquatic resource procurement. Journal of Archaeological Science: Reports, 2016, 6, pp.633-636. 10.1016/j.jasrep.2015.05.013 . hal-03146975

\section{HAL Id: hal-03146975 https://hal.science/hal-03146975}

Submitted on 19 Feb 2021

HAL is a multi-disciplinary open access archive for the deposit and dissemination of scientific research documents, whether they are published or not. The documents may come from teaching and research institutions in France or abroad, or from public or private research centers.
L'archive ouverte pluridisciplinaire $\mathbf{H A L}$, est destinée au dépôt et à la diffusion de documents scientifiques de niveau recherche, publiés ou non, émanant des établissements d'enseignement et de recherche français ou étrangers, des laboratoires publics ou privés. 


\title{
Review Article
}

\author{
Sébastien Villotte ${ }^{1}$, Christopher J. Knüsel ${ }^{2}$ \\ ${ }^{1}$ CNRS, PACEA, UMR 5199, Pessac, France \\ ${ }^{2}$ Université de Bordeaux, PACEA, UMR 5199, Pessac, France
}

\section{Title: External auditory exostoses and prehistoric aquatic resource procurement}

Short title: External auditory exostoses in Prehistory

\section{Correspondence to:}

Sébastien Villotte

Anthropologie des Populations Passées et Présentes,

UMR5199 PACEA, Université de Bordeaux - CNRS.

Batiment B8, Allée Geoffroy Saint Hilaire,

CS 50023

France - 33615 PESSAC CEDEX

E-mail: s.villotte@pacea.u-bordeaux1.fr 
Keywords: Activity-related skeletal morphologies; Aquatic resource exploitation; subsistence strategies; Sexual division of labor

\begin{abstract}
:
External auditory exostoses (EAEs) are osseous exostoses that form in the external auditory canal as a result of an irritation of the periosteum. Many conditions can be responsible for this irritation, but contact with cold water is the principal cause. This article is a brief review of clinical and anthropological studies that permit consideration of EAEs as faithful markers of water-related activities in past populations and discusses the potential as well as the limits of EAEs to provide insights into aquatic resource exploitation by prehistoric humans.
\end{abstract}




\section{Introduction}

Activity-related skeletal morphologies (also called osseous markers of activity, occupational stress markers), are acquired morphological variations, (i.e. those that are not genetic but acquired during growth and development (see Knüsel, 2000)), pathological or otherwise, related to the plasticity of bone in response to applied stress during life (Kennedy, 1989). Bioarchaeologists and palaeopathologists use such morphological changes to indicate physical activities performed by an individual during life. Among these, one - external auditory exostosis - is particularly implicated in repeated contact with cold water at an individual level and with the exploitation of aquatic resources at the population level.

\section{Presentation and Etiology}

External auditory exostoses (EAEs) are osseous exostoses that form in the external auditory canal (Fig.1; Di Bartolomeo, 1979; Leonetti and Marzo, 2014; Roland and Marple, 1997). They are caused by an irritation of the periosteum in this canal (Di Bartolomeo, 1979; Harrison, 1962). Many conditions (e.g., otitis externa, eczema, trauma, infection) can be responsible for this irritation (Di Bartolomeo et al., 1991), but contact with cold water is the chief cause. A considerable number of clinical studies demonstrate that individuals regularly exposed to cold water are most predisposed to develop EAEs. Many of these clinical studies concentrate on surfers, but also on the condition in sailors, kayakers, swimmers, water polo players, and divers (Adams, 1951; Altuna Mariezkurrena et al., 2005; Chaplin and Stewart, 1998; Cooper et al., 2010; Deleyiannis et al., 1996; Di Bartolomeo, 1979; Filipo et al., 1982; Fowler and Osmun, 1942; Harrison, 1962; Hurst et al., 2004; Ito and Ikeda, 1998; Karegeannes, 1995; Kroon et al., 2002; Timofeev et al., 2004; Van Gilse, 1938). 
It has been demonstrated that repeated irrigation of the ear eventually leads to new bone formation in guinea pigs (Fowler and Osmun, 1942; Harrison, 1962), and these and other experimental results clearly illustrate the way in which EAEs develop. Firstly, it has been shown that cold water frequently deposited in small quantities in the external auditory canal produces, in guinea pigs and humans, marked erythema due to an induced reflex vasodilation leading to increased tension in the periosteum (Harrison 1962). Secondly, from studies elsewhere in the body we know that increased normal tension of the periosteum enhances bone formation (Amprino, 1985; Glucksmann, 1942). Moreover, clinical and experimental studies provide a number of complementary results, especially with respect to temperature and the necessary exposure time. The colder the water, the longer vasodilation is sustained (Harrison 1962). Kroon et al. (2002) report that cold water surfers (below $15.5^{\circ} \mathrm{C}$ ) are two to three times more likely to develop exostoses and four times more likely to have more severe changes than surfers in warmer water. EAE is a progressive pathological condition. Exostoses may appear in susceptible individuals after one to three years of regular contact with water (Adams, 1951, Van Gilse, 1938), but 5-10 years of exposure seems the most common period of time necessary to develop a bony outgrowth (Altuna Mariezkurrena et al., 2005; Chaplin and Stewart, 1998; Cooper et al., 2010; Deleyiannis et al., 1996; Di Bartolomeo, 1979). A number of studies demonstrate a clear correlation between the time exposed and the prevalence and severity of EAE (Altuna Mariezkurrena et al., 2005; Chaplin and Stewart, 1998; Cooper et al., 2010; Deleyiannis et al., 1996; Hurst et al., 2004; Ito and Ikeda, 1998; Karegeannes, 1995; Kroon et al., 2002; Van Gilse, 1938). Clinical reports also show that ears exposed to a combination of water and cold air as represented by wind chill are more likely to develop EAE, and at a faster rate (Hurst et al., 2004; Ito and Ikeda, 1998; Timofeev et al., 2004). There might be a particular temperature threshhold that triggers the formation of exostosis - for instance water at $19^{\circ} \mathrm{C}$ is enough to produce bone formation in ginea pigs 
(Fowler and Osmun, 1942) - but as several factors interact, this temperature is diffult to define: exostosis may appear following either a severe stimulus (very low temperature) applied for a short time or a mild stimulus applied over a lengthier period of time (Harrison, 1962).

\section{[INSERT FIGURE 1 HERE]}

\section{Biological Anthropological studies, and the "thermal aquatic hypothesis"}

EAE has been extensively studied in past populations (e.g. for recent studies: Agelerakis and Serpanos, 2002; Ascenzi and Balistreri, 1975; Crowe et al., 2010; Dutour and OnrubiaPintado, 1991; Frayer, 1988; Kennedy, 1986; Manzi et al., 1991; Okumura et al., 2007; Özbek, 2012; Ponce et al., 2008; Standen et al., 1997; Villotte et al., 2014). In biological anthropology, EAEs have for a long time been considered a non-metric trait (Berry and Berry, 1967), and their origin has been discussed previously (for review, see Kennedy 1986). However, only a minority of authors (e.g. Hutchinson et al., 1997) have challenged the aquatic-related etiology of EAE after Kennedy's seminal work on the subject (1986). ${ }^{1}$ From a synthesis of published and unpublished sources she tested the "thermal aquatic hypothesis" based on the frequency of EAE by latitude. Her analysis shows very high frequencies among communities exploiting either marine or fresh water resources between $30^{\circ}$ and $45^{\circ}$ latitude north and south of the equator. EAE is, however, absent or occurs in very low frequencies in the two other areas defined as tropical / subtropical (0-30 north and south latitude) and polar / sub-polar (beyond $45^{\circ}$ north latitude, as there were no available data for populations living beyond $45^{\circ}$ south). There are very low frequencies in populations living beyond $45^{\circ}$ north latitude, given the risk of lethal hypothermia in very cold water. Support for this association has recently been provided by a study of the southernmost archaeological populations from Tierra del Fuego. They, too, show very low frequencies of EAE (Ponce et al., 2008). Because 
the temperature of the waters of the tropics is relatively warm these tropical / subtropical areas are characterised by low frequencies as well (Kennedy, 1986). However, more recent studies note frequent EAE development in population samples living in areas between $0-30^{\circ}$ north and south latitude, where cold streams lead to sea waters that are relatively cooler than expected according to latitude, or where the water is warmer but with relatively low atmospheric temperatures and strong wind chill (Okumura et al., 2007; Standen et al., 1997; Velasco-Vazquez et al., 2000).

\section{Potential of EAE linked to aquatic resource exploitation by prehistoric humans}

Studying EAE can be useful to explore many aspects of aquatic resource exploitation in prehistoric populations. The most common approach is to compare frequencies of EAE in groups living in different environments, usually from coastal and inland regions (e.g. Okumura et al., 2007; Standen et al., 1997; Velasco-Vazquez et al., 2000). Not surprisingly, these studies show significant differences between samples, those from coastal regions having higher frequencies. Another aspect often discussed is the sexual division of labor in Prehistory. In some studies no clear sexual differences are seen, at least at the statistical level of significance (e.g. Dutour and Onrubia-Pintado, 1991; Okumura et al., 2007; VelascoVazquez et al., 2000; Villotte et al., 2014), suggesting that both sexes were engaged in aquatic activities in these groups, while in other studies a significant difference is shown, usually with males having higher frequencies (e.g. Kennedy, 1986; Özbek, 2012; Standen et al., 1997). Some authors have also attempted to track differences between groups according to the type of economy. For instance, it has been shown that European Neolithic skeletons display significantly fewer EAE than Mesolithic ones (Villotte et al., 2014). This clear diachronic change is seen at the European scale as well as at the regional scale (in the Iron Gates region), 
and provides a strong argument for a rapid abandonment of marine/freshwater resources after the Mesolithic/Neolithic transition in Europe. In their study of prehistoric Chilean populations, Standen et al. (1997) show that, contrary to what was expected, coastal groups with an agriculture-based subsistence present a greater prevalence of EAE than earlier fishergatherers. They formulated the hypothesis that, in these groups with agriculture, "... those who devoted themselves to fishing were probably intensifying their activities to create a surplus for trading with inland agro-pastoral groups." (Standen et al., 1997, p. 126). The study of EAEs in a skeletal sample may also provide insights into fishing practices, as in the Iron Gates region of Serbia and Romania (Frayer, 1988; Villotte et al., 2014). Another promising approach, initiated for historical samples by Crowe et al. (2010), is to analyze individual isotopic values and EAE presence or absence conjointly. This can provide better-supported insights into whether or not individuals involved in fishing activities in prehistoric populations were also the consumers of aquatic resources (for the Iron Gates, see Villotte et al., 2014).

\section{Limits}

The study of EAE has some potential pitfalls, as with virtually all activity-related skeletal morphologies because of their multiple, albeit context-specific etiologies (Dutour, 1992; Jurmain et al., 2012; Villotte, 2008), that are necessary to consider prior to invoking aquatic resource exploitation by prehistoric humans.

\subsection{Recording EAEs}

Several methods are employed to record the presence and severity of EAEs in clinical and anthropological studies, usually on a 3 or 4 -grade scale (e.g. Crowe et al., 2010; Cooper et al., 
2010; Hurst et al., 2004; Ito and Ikeda, 1998; Özbek, 2012; Standen et al., 1997; VelascoVazquez et al., 2000; Villotte et al., 2014). The rate of inter-observer error for qualitative methods can be quite high, however (5 to 15\% according to Gregg and McGrew, 1970; Villotte et al., 2014, but see Crowe et al., 2010), likely due to lack of clear definition of the transition between grades. For instance, Hurst et al. (2004) and Villotte et al. (2014) noted that early EAE (i.e. grade 1) are sometimes difficult to grade in living people and in skeletal remains alike. At the present time, we suggest the use of the 4-grade scale defined by Standen et al. (1997) and illustrated in Crowe et al. (2010), and Cooper et al. (2010): Grade 0: no occlusion; Grade 1: occlusion of the meatus by up to one-third; Grade 2: one to two-thirds occlusion; Grade 3: more than two-thirds occlusion. According to Di Bartolomeo et al. (1991, p. 1252) "the first response of the bony ear canal to hypothermia is a change in the configuration of the oval bony external auditory canal lumen to a V-shaped configuration [...]." However, in our opinion, a grade of 1 should be allotted only when an osseous exostosis - even a slight one - is clearly distinguishable in the wall of the external auditory canal (e.g. Fig. 1a), because it seems extremely subjective to identify slight changes of the configuration of the external meatus (cf. Villotte et al. 2014, contra Hurst et al. 2004). In order to permit meaningful comparisons between large worldwide samples, methodological research based on sketches and pictures is necessary, and testing the rate of inter-observer error of this new standardized method applied to both defleshed bones and living patients is required. This is beyond the scope of the present review.

\subsection{Differential diagnosis}

The differential diagnosis for EAE includes osteomata. The latter are a rare, pedunculated, solitary and unilateral bone formations, often found attached to the tympanosquamous or 
tympanomastoid suture, while EAEs are broad-based growths of bone, usually with multiple and bilateral implantations, but which spare the sutures (Di Bartolomeo, 1979; Filipo et al., 1982; Leonetti and Marzo, 2014; Roland and Marple, 1997; White et al., 2012).

\subsection{Genetic predispositions and individual susceptibility}

Individual differential susceptibility to cold water contact was experimentally detected (Harrison, 1962) and is shown in many clinical surveys. Some individuals do not develop EAE, even if they are frequently engaged in aquatic activity (e.g. Cooper et al. 2010; Karegeannes, 1995). Conversely, EAEs develop earlier and faster in some subjects who appear to be more susceptible to the effects of cold water (Adams, 1951, Van Gilse, 1938). Comparison of frequencies between human groups may be blurred by genetic differences, but as shown by the comprehensive review done by Kennedy (1986), behavioural/environmental factors overwhelmingly predominate in the appearance of EAE.

\subsection{Other causes}

Hutchinson et al. (1997) argue that otitis externa, which is due to a wide variety of chemical, biological, or other stimulating factors, could be a cause of EAE and that "cold water is not a sufficient exclusive aetiology for external auditory exostoses given the wealth of clinical information regarding otitis externa" (Hutchinson et al., 1997 p. 421). However, this opinion is controversial. For instance, one can read in Adams (1951, p. 425) the following observation: "Mr. R. R. Simpson said that he spent three years in Ceylon [warm water] during the war where he had records of over 6,000 cases of otitis externa. Among the men there, who were accustomed to frequent bathing, otitis externa was extremely common and exostoses 
extremely rare." Moreover, it is generally admitted that otitis externa could be a result of accumulation of debris medial to the EAE (Altuna Mariezkurrena et al., 2005; Cooper et al., 2010), and thus not a cause of EAE. However, it is true that infection, eczema, trauma, or other pathological conditions affecting the normal homeostasis of the external ear canal may cause an auditory exostosis in a very small number of individuals (Di Bartolomeo et al., 1991; Fowler and Osmun, 1942). As a consequence EAE should not be used as a marker of aquatic activities in case studies of single prehistoric individuals.

\subsection{Interpreting frequencies}

The absence of EAE does not exclude aquatic activities, as individuals may protect their ears (Okumura et al., 2007; Van Gilse, 1938). Moreover, EAE is a progressive pathological condition and, as noted by Crowe and collaborators (2010), some young adults frequently in contact with cold water may have died before developing the condition. Also, as indicated above, some individuals do not develop EAE, even if they are frequently engaged in aquatic activities. As a consequence, the frequency of EAE in a sample probably underestimates the exact number of individuals involved in aquatic activities, but it can be used as a proxy to discuss the relative importance of these activities for the group. As EAE usually appears after 5 to 10 years of exposure to cold water (Altuna Mariezkurrena et al., 2005; Chaplin and Stewart, 1998; Cooper et al., 2010; Deleyiannis et al., 1996; Di Bartolomeo, 1979), it is rarely seen in immature individuals. To our knowledge, there is no systematic study of EAEs in children but Adams (1951, p. 424) reports 14 cases out of "18 boys aged 13 to 19 years, who were members of a public school swimming team, with a swimming history of from two to eight years." So, in theory, EAEs can be recorded in immature prehistoric skeletons. In that case, it seems necessary to separate the frequency for immature individuals from that of 
adults, as frequency for the whole sample would likely be related to the demographic profile of the studied group.

Interpretation of high frequencies of $\mathrm{EAE}$ in prehistoric population samples is often straightforward and related to subsistence strategies (e.g. Özbek 2012, Standen et al., 1997, Velasco-Vazquez et al., 2000). Although this marker indicates frequent contact with cold water, it reveals nothing in itself about the particular activity practiced: fishing, diving, but also bathing, for instance.

\section{Conclusions}

To summarize the clinical and anthropological findings, repeated presence of water in the external auditory meatus has been linked to the development of EAE. Despite the limitations of interpreting EAE frequencies in skeletal collections in the absence of ethnographic documentation, iconographic or textual sources, it is clear that frequencies of EAE can be considered as a proxy for water-related activities for populations and represent a useful indicator linking aquatic resource exploitation by prehistoric people living in the middle latitudes. For many reasons EAE is one of the most informative of activity-related skeletal morphologies: it has a very well known etiology, the amount of available clinical data is substantial, and it is possible to make comparisons of frequencies between current and past populations, with only minor methodological problems. When high frequencies are found in large prehistoric samples, it can be only explained as resulting from frequent contact with water for the greater part of the population. However, more precise interpretations should be assessed in conjunction with the archaeological context, rock art, tools and other material culture, faunal remains, and isotopic analyses. This requires collaboration between archaeologists, archaeozoologists, archaeological scientists, and biological 
anthropologists/bioarchaeologists. Regional studies that take into account palaeoenvironmental reconstructions and where isotope data and EAE are analyzed conjointly would provide reliable insights into aquatic resource exploitation by prehistoric humans.

\section{Acknowledgements}

A part of this research was done while the first author was supported by a post-doctoral fellowship from the the Fondation Fyssen.

\section{References}

Adams, W.S., 1951. The aetiology of swimmer's exostoses of the external auditory canals and of associated changes in hearing, The Journal of Laryngology \& Otology 65, 424-425.

Agelerakis, A., Serpanos, Y., 2002. On the prevalence of external auditory exostoses among the protoneolithic Homo sapiens population of Shanidar Cave, Iraq, Human evolution 17, 247-252.

Altuna Mariezkurrena, X., Gómez Suárez, J., Luqui Albisua, I., Vea Orte, J.C., Algaba Guimerá, J., 2005. Prevalence of exostoses among surfers of the Basque Coast, Acta Otorrinolaringológica Española 55, 364-368.

Amprino, R., 1985. The influence of stress and strain in the early development of shaft bones, Anat. Embryol. 172, 49-60.

Ascenzi, A., Balistreri, P., 1975. Aural exostoses in a Roman skull excavated at the "Baths of the Swimmer" in the ancient town of Ostia, J. Hum. Evol. 4, 579-584.

Berry, C.A., Berry, R., 1967. Epigenetic variation in the human cranium, J. Anat. 101, 361.

Chaplin, J.M., Stewart, I.A., 1998. The prevalence of exostoses in the external auditory meatus of surfers, Clinical Otolaryngology \& Allied Sciences 23, 326-330.

Cooper, A., Tong, R., Richard Neil, Owens, D., Tomkinson, A., 2010. External auditory canal exostoses in white water kayakers, Br J Sports Med 44, 144-147. 
Crowe, F., Sperduti, A., O'Connell, T.C., Craig, O.E., Kirsanow, K., Germoni, P., Macchiarelli, R., Garnsey, P., Bondioli, L., 2010. Water-related occupations and diet in two Roman coastal communities (Italy, first to third century AD): Correlation between stable carbon and nitrogen isotope values and auricular exostosis prevalence, Am. J. Phys. Anthropol. 142, 355-366.

Deleyiannis, F.W.B., Cockcroft, B.D., Pinczower, E.F., 1996. Exostoses of the external auditory canal in Oregon surfers, American Journal of Otolaryngology 17, 303-307.

Di Bartolomeo, J., 1979. Exostoses of the external auditory canal, Ann. Otol. Rhinol. Laryngol. 88.

Di Bartolomeo, J., Paparella, M., Meyerhoff, W., 1991. Cysts and tumors of the external ear, in: Shumrick, D., Gluckman, J., Meyerhoff, W. (Eds.), Otolaryngology, 3rd ed., Vol. 2, Saunders, Philadelphia, pp. 1243-1258.

Dutour, O., Onrubia-Pintado, J., 1991. Interactions homme-environnement océanique pendant la Préhistoire récente des Iles Canaries : nouvelles données paléoanthropologiques de la Région de Galdar (Grande Canarie), Comptes Rendus de l'Académie des Sciences. Série 3, Sciences de la Vie $313,125-130$.

Dutour, O., 1992. Activités physiques et squelette humain : le difficile passage de l'actuel au fossile, Bull. Mem. Soc. Anthropol. Paris n.s., 4, 233-241.

Filipo, R., Fabiani, M., Barbara, M., 1982. External ear canal exostosis: a physiopathological lesion in aquatic sports, J Sports Med Phys Fitness 22, 329-336.

Fowler, E.P., Osmun, P.M., 1942. New bone growth due to cold water in the ears, Archives of otolaryngology $36,455-466$.

Frayer, D.W., 1988. Auditory exostoses and evidence for fishing at Vlasac, Curr. Anthropol. 29, 346349.

Glucksmann, A., 1942. The role of mechanical stresses in bone formation in vitro, J. Anat. 76, 231239.

Gregg, J. B., McGrew R. N., 1970. Hrdlicka revisited (external auditory canal exostoses). American Journal of Physical Anthropology 33, 1: 37-40.

Harrison, D.F.N., 1962. The relationship of osteomata of the external auditory meatus to swimming, Ann R Coll Surg Engl. 31, 187-201. 
Hurst, W., Bailey, M., Hurst, B., 2004. Prevalence of external auditory canal exostoses in Australian surfboard riders, The Journal of Laryngology \& Otology 118, 348-351.

Hutchinson, D.L., Denise, C.B., Daniel, H.J., Kalmus, G.W., 1997. A reevalution of the cold water etiology of external auditory exostoses, Am. J. Phys. Anthropol. 103, 417-422.

Ito, M., Ikeda, M., 1998. Does cold water truly promote diver's ear?, Undersea Hyperb. Med 25, 5962.

Jurmain, R., Alves Cardoso, F., Henderson, C.Y., Villotte, S., 2012. Bioarchaeology's Holy Grail: The Reconstruction of Activity, in: Grauer, A.L. (Ed.), A Companion to Paleopathology, Wiley-Blackell, New-York, pp. 531-552.

Karegeannes, J.C., 1995. Incidence of bony outgrowths of the external ear canal in U.S. Navy divers, Undersea Hyperb. Med 22, 301-306.

Kennedy, G.E., 1986. The relationship between auditory exostosis and cold water: A latitudinal analysis, Am. J. Phys. Anthropol. 71, 401-415.

Kennedy, K.A.R., 1989. Skeletal markers of occupational stress, in: Iscan, M.Y., Kennedy, K.A.R. (Eds.), Reconstruction of life from the skeleton, Liss, New York, pp. 130-160.

Knüsel, C.J., 2000. Bone adaptation and its relationship to physical activity in the past, in: Cox, M., Mays, S.A. (Eds.), Human Osteology in Archaeology and Forensic Science, Greenwich Medical Media, London, pp. 381-401.

Kroon, D.F., Lawson, M.L., Derkay, C.S., Hoffmann, K., McCook, J., 2002. Surfer's ear: External auditory exostoses are more prevalent in cold water surfers, Otolaryngology- Head and Neck Surgery $126,499-504$.

Leonetti, J.P., Marzo, S.J., 2014. Disease of the External Auditory Canal (4th Ed), in: Pensak, M.L., Choo, D.I. (Eds.), Clinical Otology, Thieme, Stuttgart, pp. 181-191.

Manzi, G., Sperduti, A., Passarello, P., 1991. Behavior-induced auditory exostoses in Imperial Roman society: Evidence from coeval urban and rural communities near Rome, Am. J. Phys. Anthropol. 85, 253-260. 
Okumura, M.M.M., Boyadjian C. H.C., Eggers, S., 2007. Auditory exostoses as an aquatic activity marker: A comparison of coastal and inland skeletal remains from tropical and subtropical regions of Brazil, Am. J. Phys. Anthropol. 132, 558-567.

Özbek, M., 2012. Auditory exostoses among the Pre-Pottery Neolithic inhabitants of Çayönü and Aş1kl1, Anatolia; its relation to aquatic activities, International Journal of Paleopathology 2, 181-186.

Ponce, P., Ghidini, G., González-José, R., 2008. External auditory exostosis "at the end of the world" the southernmost evidence according to the latitudinal hypothesis, in: Brickley, M., Smith, M. (Eds.), Proceedings of the Eighth Annual Conference of the British Association for Biological Anthropology and Osteoarchaeology. British Archaeological Reports S1743, Archaeopress, Oxford, pp. 101-107.

Roland, P., Marple, B., 1997. Disorders of the external auditory canal, J Am Acad Audiol. 8, 367-378. Standen, V.G., Arriaza, B.T., Santoro, C.M., 1997. External auditory exostosis in prehistoric Chilean populations: A test of the cold water hypothesis, Am. J. Phys. Anthropol. 103, 119-129.

Timofeev, I., Notkina, N., Smith, I.M., 2004. Exostoses of the external auditory canal: a long-term follow-up study of surgical treatment, Clinical Otolaryngology 29, 588-594.

Van Gilse, P.H.G., 1938. Des obervations ultérieures sur la genèse des exostoses du conduit externe par l'irritation d'eau froide, Acta Otolaryngol, 343-352.

Velasco-Vazquez, J., Betancor-Rodriguez, A., Arnay-De-La Rosa, M., Gonzalez-Reimers, E., 2000. Auricular exostoses in the prehistoric population of Gran Canaria, Am. J. Phys. Anthropol. 112, 49-55. Villotte, S., 2008. Les marqueurs ostéoarticulaires d'activité, in: Charlier, P. (Ed.), Ostéo-archéologie et Techniques Médico-légales: Tendances et Perspectives. Pour un "Manuel Pratique de Paléopathologie Humaine", Editions De Boccard, Paris, pp. 383-389.

Villotte, S., Stefanović, S., Knüsel, C.J., 2014. External auditory exostoses and aquatic activities during the Mesolithic and the Neolithic in Europe: Results from a large prehistoric sample, Anthropologie LII, 73-89.

White, R.D., Ananthakrishnan, G., McKean, S.A., Brunton, J.N., Hussain, S.S.M., Sudarshan, T.A., 2012. Masses and disease entities of the external auditory canal: Radiological and clinical correlation, Clinical Radiology 67, 172-181. 


\section{Endnotes}

${ }^{1}$ It should be noted, however, that many biological anthropologists still considered EAE mainly as a marker for diving (Villotte, pers. obs.). Diving can indeed lead to the formation of EAE, but it seems "... that people participating in 'above water' activities, such as surfing and sailing, develop severe exostoses significantly faster than sportsmen in the "underwater' group (divers, swimmers)." (Timofeev et al., 2004, p. 583).

\section{Figure Captions}

Figure 1. Several examples of minor manifestations of external auditory exostoses. In each case, the occlusion of the meatus is less than one-third. a) A very slight single, broad-based swelling on the posterior canal wall. b) A larger, broad-based swelling on the posterior canal wall. c) Two small rounded nodules on the supero-anterior bony wall. 
Figure

Click here to download high resolution image
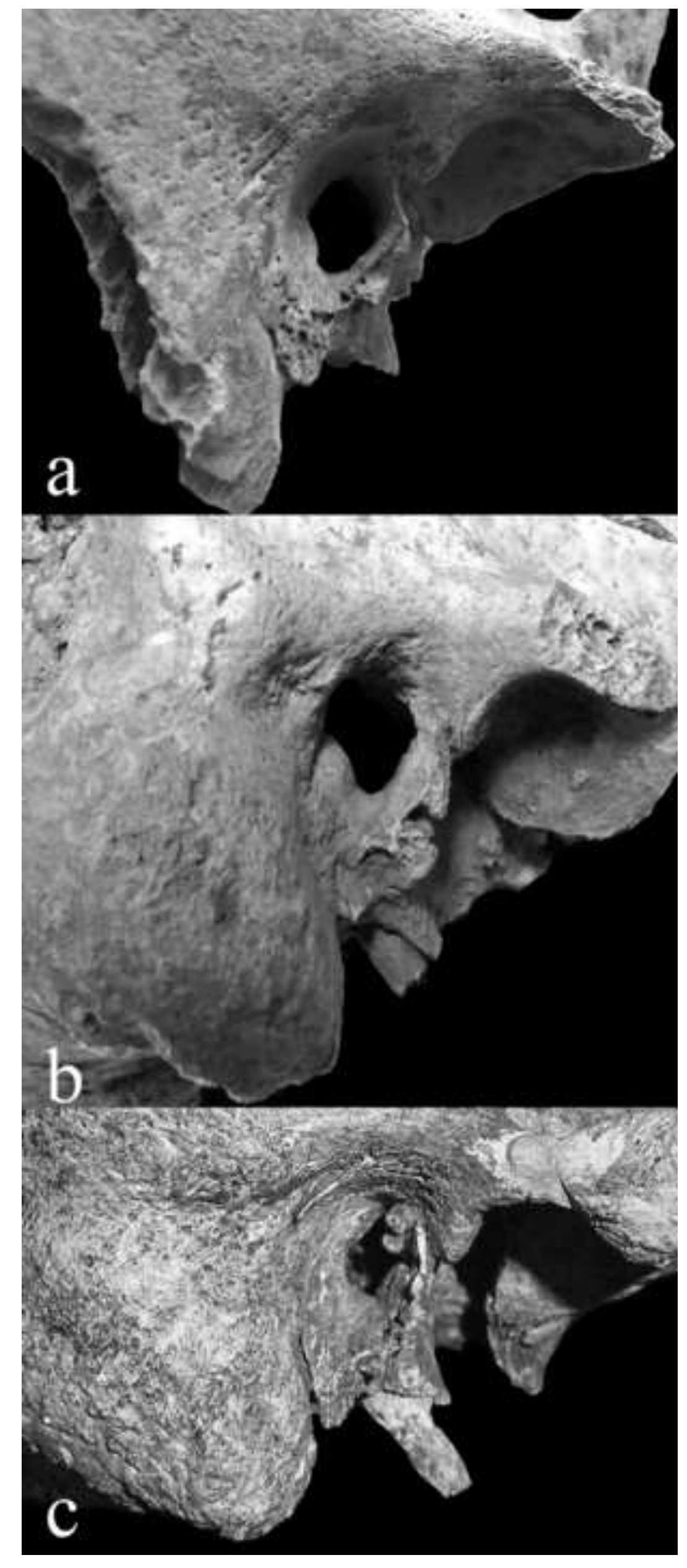

(2) 